\title{
IDENTIDADE E INTERTEXTUALIDADE: A CON- STRUÇÃO DO GÊNERO E DA SEXUALIDADE NA PREVENCCÃO DE DST/AIDS ENTRE TRAVESTIS QUE SE PROSTITUEM
}

\author{
Rodrigo Borba
}

\begin{abstract}
This paper discusses the construction of gender and sexual identities as intertextual phenomena that emerge from local contexts of language use. More specifically, guided by a non-representational/non-essencialist perspective on language use and identity, this article investigates the discursive construction of identities in interactions drawn from safer-sex outreach work among tranvestis who work as sex professionals in an urban area in Southern Brazil. During the safer-sex outreach work interactions, Sandra and Márcia, women in gender and sex, produce non-traditional identities and bring to light interactional processes of adequation of their subject positions to the travestis' and to the context of the interactions. Based on Wittgenstein's (2005) and Bakhtin's (2003; 2004) theories, I argue that the discursive production of identities is only made possible because of the intertextual aspect of social identities. Sandra and Márcia make use of intertexts that construct them as participants of the travestis' social universe. The safer-sex outreach workers position themselves through their utterances in identity categories such as travesti, travesti's client, and prostitute and, thus, seem to engage in sequential processes of adequation of their subject positions to their transgendered interlocutors.
\end{abstract}

Key words: Intertextuality, identity, safer sex.

Com o presente texto, trago à baila uma discussão sobre a construção de identidades de gênero e de sexualidade em embates interacionais situados nas zonas de prostituição travesti de uma região urbana do sul do Brasil. As interações sob escrutínio são co-construídas entre duas mulheres, Sandra e Márcia, ativistas de uma organização não-governamental (doravante ONGLiberdade) que visa à melhoria da qualidade de vida das travestis da Cidade 
do $\mathrm{Sul}^{1}$ e travestis que se prostituem nessa cidade. Mais especificamente, essas interações são fruto de um projeto da ONG-Liberdade que consiste na entrega de preservativos às travestis enquanto essas vendem sexo nas ruas da Cidade do Sul. Durante tais interações, as ativistas da ONG, que, em seu cotidiano, se constroem como participantes de grupos identitários hegemônicos de gênero, raça e classe social, re-constroem-se discursivamente como indivíduos participantes do mundo da prostituição. Argumenta-se que tal trânsito por uma miríade de discursos de identidades só é possível pelo caráter intertextual das identidades sociais. Veremos que a produção discursiva de identidades é uma ação intertextual par excellence no sentido de que para se construírem de diferentes formas na zona de prostituição, Sandra e Márcia apropriam-se de vozes pertencentes a discursos não-tradicionais de gênero e sexualidade nos embates interacionais co-construídos entre elas e as travestis recebem os preservativos durante seu trabalho prevenção de DST/aids nos territórios de prostituição da cidade, chamados de zona batalha. ${ }^{2}$

Para desenvolver meu argumento me baseio nas idéias de Wittgenstein (2005; Glock, 1998; Moreno, 2000; Marcondes, 2000; Martins, 2000 e Strathern, 1997) e Bakhtin (2003; 2004; Clark \& Holquist, 1998; Stam, 2000). Do primeiro, tomo emprestada a visão não-representacional da linguagem. $\mathrm{Na}$ teoria wittgensteiniana, a linguagem é considerada não como um instrumento de representação do mundo, mas, sim, como uma ferramenta para agir sobre o mundo. Isso pode ter fortes implicações para o estudo de identidades sociais, pois, ao afirmar que não existe significado anterior à práxis lingüística (Martins, 2000), Wittgenstein nos impele a considerar as identidades (das coisas e das pessoas) como construídas lingüisticamente em nossas interações cotidianas. Para explicitar a construção intertextual das identidades das interventoras, recorro à teoria bakhtiniana da linguagem. Mais precisamente, faço uso dos conceitos de dialogismo e polifonia sobre os quais estruturo minhas análises enfatizando o caráter polifônico das identidades construídas pelas ativistas da ONG-Liberdade.

1. Por motivos de caráter ético, utilizo pseudônimos para me referir às participantes das interações, à cidade onde os dados foram gerados e a lugares mencionados pelas informantes durante o período de trabalho de campo.

2. Termo êmico utilizado pelas travestis para se referir ao ato da prostituição. 


\section{ConteXto E Metodologia de PeSQUISA}

Baseado em dados gerados durante 12 meses de trabalho de campo de cunho etnográfico realizado durante os anos de 2003 e 2004, trago à baila uma discussão sobre intervenções para prevenção de DST/aids elaboradas pela ONG Liberdade entre travestis que se prostituem em uma região urbana do sul do Brasil. Durante as intervenções, duas mulheres empregadas na ONG, Márcia, a secretária, e Sandra, a advogada, entregam preservativos às travestis ${ }^{3}$ e constroem interações que parecem ser estruturadas com base na construção intertextual das identidades de gênero e de sexualidade das interventoras e das travestis com quem trabalham.

No ano de 2003, durante a realização de outra pesquisa sobre travestis (Borba \& Ostermann, 2007), fui alertado, em uma entrevista com a travesti coordenadora da ONG Liberdade, sobre a realização dessas intervenções. Logo me interessei. Tendo recebido permissão da ONG e o consentimento das travestis e das interventoras para gravar em áudio as interações, comecei a acompanhar as entregas dos preservativos. É importante observar, contudo, que eu não entregava as camisinhas. Portanto, eu não era um participante ativo dos eventos. Minha participação nesses eventos era de observador. Minha presença (e a presença do gravador) era sempre feita explícita às travestis abordadas pela equipe.

O subcorpus de dados aqui analisado foi gerado no período de setembro a dezembro de 2003. Durante esses meses, acompanhei a equipe em cinco intervenções que foram gravadas e transcritas. Aproximadamente 12 abordagens ocorriam por intervenção o que constitui um total de sessenta interações e mais de 8 horas de gravação. Ademais, os dados gerados durante os 12 meses de trabalho de campo constituem um corpus de aproximadamente 60 horas de gravações que engloba: gravações de conversas espontâneas na sede da Liberdade, notas de campo sobre as práticas das travestis dentro e fora dos seus territórios de prostituição, entrevistas semi-estruturadas com travestis e interventoras elaboradas na sede da Liberdade. É importante enfatizar, porém, que as análises a serem apresentadas aqui são primordialmente baseadas nas gravações das intervenções.

3. Utilizo o feminino gramatical ao me referir às travestis durante o texto. Além de um posicionamento político, essa escolha converge com o uso feito por travestis nas mais diferentes localidades do Brasil na tentativa de construir sua identidade discursiva de acordo com sua performance de gênero (Butler, 2003). Para uma discussão sobre o assunto ver Borba e Ostermann (2007). 


\section{SOCIOCONSTRUCIONISMO: DA IDENTIDADE COMO FENOMMENO DISCURSIVO}

Consideremos a cena abaixo, retirada das notas de campo elaboradas durante meu trabalho em parceria com a ONG Liberdade:

Conversávamos em tom deliciosamente informal na sede da Liberdade em uma quente tarde de quarta-feira. Cassiana, sempre muito bem informada, contava as novidades sobre as 'monas' 4 da Cidade do Sul: Cynthya estava 'batendo porta's como prostituta em Paris; chegara à cidade uma travesti be-lis-si-ma nascida em Manaus; Suzi andava 'sumida' pois estava envolvida em rituais do candomblé; Thalia fora impedida de entrar no banheiro feminino de um shopping e fez um escândalo... Todas essas informações eram comentadas em diferentes tonalidades: ironia, sarcasmo, risos e muitos conselhos. Bárbara, em certo momento, fala sobre sua nova estratégia de inserção no mercado sexual da cidade: anunciaria seus serviços em classificados de jornais! Cassiana e Marcela, respectivamente coordenadora e tesoureira da ONG, já haviam utilizado tal recurso e aproveitam a oportunidade para aconselhar a iniciante. Bárbara deveria escolher o jornal de acordo com seu público alvo. Além disso, a compra de um celular exclusivo para o serviço deveria ser agilizada e, o mais importante, o texto do anúncio teria que ser muito bem pensado. Todas presentes sugeriram um possivel texto. Até mesmo eu tentei ajudar. Minutos depois, Bárbara, entusiasmada, tem uma idéia que, segundo ela, atrairia muitos clientes. Porém, manteve segredo (afinal, alguma presente poderia roubá-la). Dias depois, recebo uma ligação, Bárbara pedia minha opinião sobre seu anúncio. Abro o jornal e procuro a página por ela indicada. Lá en-

4. Termo êmico que se refere às travestis. Parece-me que a escolha da palavra mona, de desinência feminina, é uma forma de driblar as limitações gramaticais para construção de uma identidade de gênero coerente com a imagem feminina das travestis.

5. Termo êmico que se refere à freqüência dos programas feitos. Bater porta faz alusão ao ato de entrar e sair dos carros dos clientes. 
contro seu texto: "Bruna", corpo de Eva com o melhor de Adão”. [Diários de campo, 21/01/2004]

$\mathrm{Na}$ cena acima ilustrada, Bárbara, ao anunciar seus serviços sexuais em um jornal, faz uso de discursos que a constroem na intersecção da feminilidade e da masculinidade (Borba \& Ostermann, 2007), ilustrando, assim, o poder que o discurso tem de prover identidades às pessoas através de práticas discursivas que colocam suas vidas em sociedade. Com o intuito de "atrair muitos clientes", a anunciante faz uso de discursos que, ao serem sobrepostos, produzem o efeito de uma identidade específica: a identidade travesti. Bárbara, dona de um "corpo de Eva" que mantém "o melhor de Adão", sublinha os atributos corporais que a constroem nos limiares de discursos sobre o gênero social disponíveis em uma sociedade fortemente católica. A feminilidade, a candura e a pureza associadas à imagem bíblica de Eva são entrelaçadas à virilidade representada pelo corpo de Adão. Ao valer-se de discursos e imagens que, segundo ela, podem garantir-lhe uma boa clientela, Bárbara discursivamente apropria-se de atributos identitários que visam enfatizar a construção de sua própria identidade baseada na manipulação de uma biologia masculina na tentativa de moldar seu corpo com formas e atributos simbólicos convencionalmente ligados às mulheres. Dessa forma, o anúncio utilizado por Bárbara ilustra o aporte teórico que guia esta investigação: a visão socioconstrucionista do discurso e das identidades sociais (Moita Lopes, 2002, 2003).

Segundo essa perspectiva, nossas identidades são construídas através do discurso, não havendo, assim, uma identidade única alocada na psiché dos indivíduos. Pelo contrário, as identidades são fabricadas no momento do engajamento em algum embate discursivo (Moita Lopes, 2003; Cameron, 2001; Davies \& Harré, 1990), sendo, assim, o resultado/efeito dos processos sócioculturais e interacionais nos quais nos envolvemos cotidianamente (Moita Lopes, 2001, 2005; Hall, 2005; Bucholtz \& Hall, 2004; Bucholtz, 1999; Eckert \& Mcconnell-Ginet, 1992). Moita Lopes (2002) afirma que "as identidades sociais não estão nos indivíduos, mas emergem na interação entre os indivíduos agindo em práticas discursivas particulares nas quais estão posicionados" (p.37). Desse modo, as identidades não estão prontas nem fixas, mas situadas em processos discursivos que as constroem a partir de propósitos localmente negociados.

6. É comum entre as travestis a utilização de vários nomes que são contextualmente específicos. Assim, uma travesti tem um nome feminino para o círculo de seu convívio social, outro para a prática de prostituição rueira, mais um para a prostituição via Internet e, como no caso ilustrado, um nome específico para os anúncios em jornais. Esse padrão de uso de pseudônimos foi também descrito por Benedetti (2005:49). 
A visão socioconstrucionista do discurso e das identidades sociais é baseada na premissa de que "cada um de nós é membro de muitos Discursos, e cada Discurso representa uma de nossas múltiplas identidades" (Gee, 1990: xix). ${ }^{7}$ Consoante Gee \& Lankshear (1997), recorremos a determinados discursos "em momentos e lugares apropriados [...] para sinalizar participação em [...] um grupo social particular" (p.97). Destarte, ao nos engajarmos em algum embate discursivo, temos a oportunidade de fazer usos de determinados discursos para nos (re)construir e, simultaneamente, (re)construir nossos/as interlocutores/as como determinados tipos de pessoas.

Com isso não se afirma que acordamos a cada dia como outra pessoa completamente diferente. Muito pelo contrário. Como observa Fabrício (2006:46), "existir seria existir sempre em movimento, em meio a oscilações entre continuidades e rupturas"; é a partir dessas oscilações entre discursos de identidades que podemos perceber um certo grau de estabilidade que nos ajuda a manter uma certa coerência identitária em nossas interações. Fabrício e Moita Lopes (2004), recorrendo à filosofia da linguagem de Wittgenstein, sugerem que a

utilização do critério de identidade (em relação às coisas ou às pessoas), supondo a existência de identidades iguais a si mesmas, diz respeito a uma operação lógica, instauradora de algum grau de estabilidade para os sentidos, a qual exerce sobre nós uma força coercitiva, pois constitui uma estratégia para lidar com o caráter cambiante do significado. $\mathrm{O}$ efeito de estabilidade não seria intrínseco às idéias em jogo, mas sim atributo do uso, único responsável por certa constância na significação. Assim sendo, o conceito de identidade funciona como um conceito operacional que, subordinando-se a regras de uso que aprendemos a reificar, possibilitaria a criação de sentido entre as pessoas. (p.15)

Consoante autora e autor, a estabilidade deve ser considerada como um efeito do uso repetido de padrões identitários; não um aspecto intrínseco às identidades. Essa estabilidade só pode se percebida através de um escrutínio público que decide "o que conta como 'o mesmo"” (Fabrício \& Moita Lopes, 2004:16). Assim, ao nos movimentarmos em diversos discursos, produzimos o efeito de estabilidade ao nos colocarmos no palco interacional sobre o qual

7. Gee (1990) e Gee \& Lankshear (1997) utilizam o termo Discurso, com D maiúsculo, para se referir a modos de ser no mundo social, a diferentes formas de vida e a diferentes práticas que sinalizam diferentes identidades. Para evitar uma inflação conceitual, utilizo, no decorrer do texto, "discurso", com d minúsculo, para me referir ao mesmo conceito. 
a audiência decide o que conta como sendo nós mesmos. Outro fator importante na construção da estabilidade (operacional) das identidades é a questão da repetição de discursos que, ao serem proferidos, produzem um efeito de substância, como bem observa Butler (1990/2003). Segundo os argumentos dessa autora, as identidades parecem ser naturais e estáticas, pois os indivíduos reproduzem discursos já sedimentados na cultura, o que produz um efeito de continuidade e essência. Porém, como argumenta Butler (1990/2003), os indivíduos têm a potencialidade da repetição subversiva. Isso quer dizer que podem reificar discursos a eles disponíveis, porém, sobrepondo-os a outros significados e produzindo arranjos identitários inauditos.

Como indica Moita Lopes (2003:27), "aprendemos a ser quem somos nos encontros interacionais de todo dia". Por conseguinte, vemos que, em oposição à visão tradicional da sociolingüística variacionista, segundo o socioconstrucionismo, não falamos $\mathrm{A}, \mathrm{B}$ ou $\mathrm{C}$ porque somos $\mathrm{X}, \mathrm{Y}$ ou Z. Muito pelo contrário. Nos constituímos como X, Y ou Z ao falarmos A, B ou C. Assim, o discurso tem uma natureza constitutiva, pois ao nos engajarmos em práticas discursivas não só representamos o mundo, mas também o construímos (Fairclough, 2001; Moita Lopes, 2001, 2002, 2003, 2006).

Ao considerar as identidades como construídas no/pelo/através do discurso, nos deparamos com seu caráter contraditório, fragmentado e processual, pois em cada prática discursiva os indivíduos podem se constituir diferentemente vis-à-vis o contexto sócio-histórico-cultural específico e vis-à-vis os/as outros/as participantes da interação. Dessa maneira, por exemplo, uma mulher que habitualmente se descreve como negra, de classe trabalhadora, lésbica e mãe pode enfatizar determinados traços de seu feixe identitário (Moita Lopes, 2003) e amenizar outros por razões determinadas localmente na interação. Aqui, seguindo Moita Lopes (2002, 2003), aludo a dois aspectos importantes da visão socioconstrucionista adotada nesta investigação: a alteridade (Bakhtin, 1979/2003; 1929/1997) e a situacionalidade (Lindstrom, 1992). Em outras palavras, todo e qualquer discurso é produzido por alguém que tem marcas sóciohistóricas particulares e é direcionado a alguém, com suas marcas identitárias, em um contexto de produção específico. O anúncio de Bárbara, descrito acima, exemplifica tal processo. A travesti, enfatizando seus atributos corporais, anuncia seus serviços sexuais tendo em mente um leitor projetado ${ }^{8}$, i.e. um que se

8. Propositalmente, faço uso da generalização no masculino para me referir aos clientes das travestis, pois, como já observado por Kulick (1997, 1998), Benedetti (2005) e Pelúcio (2005), esses indivíduos têm, inexoravelmente, performances corporal, social e sexual associadas à masculinidade hegemônica. 
interesse sexualmente por um corpo que sobreponha índices de feminilidade e de masculinidade. ${ }^{9}$

Esses dois aspectos sublinham o papel social do discurso, nessa perspectiva entendido como ação sobre o mundo. Alteridade e situacionalidade indicam que "as pessoas usam a linguagem a partir de suas marcas sóciohistóricas como homens, mulheres, homoeróticos, heterossexuais, etc., ao mesmo tempo que [...] se reconstroem ao agirem uns em relação aos outros via linguagem" (Moita Lopes, 2003:25). Isso quer dizer que não usamos a linguagem com um/a falante simplesmente, mas, com, por exemplo, uma mulher, heterossexual, de classe média, feminista, branca, advogada, procedente de uma família judia ${ }^{10}$, ou, pelo menos, de acordo com nossa construção/interpretação de tal mulher. Em outras palavras, os atributos do feixe identitário de nossos/as interlocutores/as influenciam a nossa escolha de significados para a participação em um embate discursivo.

A perspectiva que direciona minha interpretação das relações entre linguagem e identidade, a visão socioconstrucionista do discurso e das identidades sociais, é fortemente estruturada sobre pressupostos wittgensteinianos e bakhtinianos. Faz-se necessário, portanto, esclarecer os conceitos propostos por esses autores mais relevantes para a investigação aqui relatada.

\section{AS IMPLICAÇÕES DAS TEORIAS DE WITTGENSTEIN E BAKHTIN PARA OS ESTUDOS DA LINGUAGEM E DAS IDENTIDADES SOCIAIS}

Os estudos lingüísticos foram inaugurados, na era moderna, pelo suíço Ferdinand de Saussure em seu Curso de Lingüística Geral publicado em 1916. Nesse livro, o objetivo da ciência da linguagem é postulado: o estudo sincrônico do sistema da língua (langue). Saussure sugere, pari passu com o estruturalismo positivista em voga na época, que a lingüística deveria ocuparse da descrição minuciosa da estrutura da língua nos mais diversos níveis: fonológico, morfológico, sintático. Influenciada pela tradição essencialista

9. Ao serem perguntadas por que são tão procuradas no mercado sexual, todas as minhas colaboradoras travestis deram respostas similares nas quais indicavam que os homens as procuram, pois desejam "uma mulher com algo a mais". É isso, me parece, que Bárbara leva em consideração ao elaborar o texto para seu anúncio. Para discussões sobre os clientes das travestis ver Kulick (1998) e Pelúcio (2005).

10. Utilizo propositalmente, como exemplo, as marcas identitárias construídas por Sandra, umas das interventoras funcionárias da ONG Liberdade que participou do presente estudo. 
que há muito guiava o pensamento das Ciências Humanas, a teoria saussureana da linguagem guiou grande parte dos estudos lingüísticos desde então. Seguindo essa perspectiva, lingüistas acreditavam que (1) os significados são entidades autônomas, i.e. com uma existência independente da realidade extra-lingüística; (2) que a função precípua da linguagem é representar tais significados, a linguagem servindo, assim, como um representante que uni o mundo real ao lingüístico; e (3) que a interação é primordialmente baseada em operações mentais de tradução e interpretação (Martins, 2000; Fabrício, 2002). Ligada a uma forte corrente positivista, a teoria de Saussure teve alto grau de aceitação.

No entanto, Wittgenstein em suas Investigações Filosóficas (2005 [1953]) contesta a perspectiva representacional proposta por Saussure e outros lingüistas e filósofos da linguagem. Com a revolução wittgensteiniana na filosofia da linguagem "referir passa a ser apenas uma entre as inúmeras facetas da linguagem" (Marcondes, 2000). Maria Helena Martins (2000:27) observa que "ao criticar a idéia de que 'damos nomes às coisas para podermos falar delas', Wittgenstein nos convida [...] a constatar as inúmeras outras funções que motivam o uso da linguagem, salientando [...] que 'falar das coisas' é somente uma delas, e [...] que, na maioria das vezes, nos referimos às coisas enquanto fazemos as mais diversas coisas com nossas sentenças". A linguagem é, nessa perspectiva, um tipo de ação, uma atividade, um comportamento, uma forma de vida em que agimos e da qual tomamos parte. Com efeito, Wittgenstein enfatiza que a linguagem é um fenômeno social por excelência.

A perspectiva não-representacional proposta por Wittgenstein é basilar para os estudos sobre as identidades sociais. Com ela, o autor nega a existência de um significado e uma identidade dados a priori, anterior à práxis lingüística. Segundo o filósofo, "o significado de uma palavra é o seu uso na linguagem" (Investigações Filosóficas, proposição 43). Devemos, então, adotar uma atitude pragmática com relação à linguagem (Conde, 1998) na qual o uso é o eixo principal do processo de significação. Essa perspectiva considera a linguagem a partir do conceito de jogos de linguagem. Com esse conceito, Wittgenstein enfatiza a multiplicidade de usos que podem ser feitos das palavras e enunciados, assim, o mecanismo de referência é relativizado e situado nos seus usos possíveis (Moreno, 2000). A linguagem é considerada como um conjunto de atividades com as quais está interligada, por exemplo, fazer uma promessa, dizer juras de amor, dar aula, fazer uma palestra, rezar, xingar, cantar, entregar preservativos a travestis. Todos esses exemplos constituem jogos cujas regras são localmente negociadas entre os/as participantes dos eventos. Dessa forma, o significado de uma palavra é dependente das regras contextuais de cada jogo. 
A visão da linguagem como indissociável do seu contexto de produção sócio-cultural é também ilustrada na obra de Mikhail Bakhtin e seu círculo. Em sua obra (Bakhtin, 1997 [1929], 2003, 2004), a langue saussureana é deixada de lado e o foco de atenção é lançado sobre a linguagem $e$ os contextos sócio-históricos de sua atualização. Bakhtin interessa-se pelo uso, ou seja, pela emissão, pela produção, pelo discurso produzido e compartilhado por seres humanos em interação social. O filósofo russo centra sua atenção sobre "o fato de que a linguagem não é falada no vazio, mas numa situação histórica e social concreta no momento e no lugar da atualização do enunciado" (Brait, 1997:97). Desse modo, Bakhtin sugere que a linguagem é um fenômeno social de interação. Para o autor, o papel principal da linguagem é a comunicação (que é sempre considerada em seu contexto sócio-histórico-cultural). Comunicar-se implica agir dialogicamente, i.e. em diálogo com interlocutores/as que estão situados/as sócio-historicamente.

Bakhtin (2003) assevera que nenhum enunciado pode ser apenas atribuído a quem o falou, pois qualquer enunciado é sempre produzido em relação dialógica. Isso quer dizer que ao emitir um determinado enunciado, o/a falante inevitavelmente o direciona a um destinatário/a que, com suas marcas sóciohistóricas de gênero, classe social, poder, etc, molda, a priori, sua produção (ver também Moita Lopes, 2003, 2006). Cada enunciado pertence imanentemente à interação entre falante e ouvinte, pois tanto produtor/a de determinado enunciado quanto seu/sua receptor/a são participantes ativos de sua emissão. O primeiro o articula em palavras, o último o molda com seu status sociointeracional. Segundo o autor,

A palavra [ou enunciado] é interindividual. Tudo o que é dito, o que é expresso, se encontra fora da 'alma' do falante, não pertence apenas a ele. A palavra não pode ser entregue apenas ao falante. $\mathrm{O}$ autor (falante) tem seus direitos inalienáveis sobre a palavra, mas seu ouvinte também tem os seus direitos; também têm seus direitos aqueles cujas vozes estão na palavra encontrada de antemão pelo autor [...]. A palavra é um drama do qual participam três personagens (não é um dueto, mas um trio) (Bakhtin, 2003:328).

Observe que para Bakhtin também têm direito sobre o enunciado aqueles/as cujas vozes um dado enunciado ecoa. Ao utilizar a linguagem, ecoamos, em nossos enunciados, as vozes de outros participantes da situação de discursiva que, de alguma forma, já emitiram discursos similares. $\mathrm{O}$ autor, no entanto, não afirma que nossos enunciados são sempre cópias de enunciados anteriores. 
Longe disso. De acordo com sua teoria social da linguagem, "o enunciado nunca é apenas um reflexo, uma expressão de algo já existente fora dele, dado e acabado. Ele sempre cria algo que não existia antes dele [...]. Contudo, alguma coisa criada é sempre criada a partir de algo dado. Todo dado se transforma em criado" (Bakhtin, 2003:326). Vê-se, então, que o enunciado emerge da interação entre falante, ouvinte e os discursos que os circulam em dado contexto social. Assim, o/a falante, ao contrário da visão saussureana da linguagem, não pode ser considerado/a o/a único/a autor/a dos enunciados que faz uso na interação. Esses enunciados são, na verdade, produtos da interação do/a falante com (1) o/a ouvinte e (2) com o contexto discursivo onde está inserido.

\section{INTERTEXTUALIDADE COMO ELEMENTO GONSTITUTIVO DO DISCURSO}

Todo enunciado deve ser creditado a, no mínimo, três fontes: ao/à falante, ao/à ouvinte e às vozes nele ecoadas. O conceito de intertextualidade é, na obra de Bakhtin, referido pelo termo polifonia. ${ }^{11}$ Para o filósofo russo, não há discurso puro. Todos os discursos (orais e escritos) são cravejados por vozes de outros que, em maior ou menor grau, já enunciaram discursos similares. Nas palavras de Bakhtin (2003:330),

cada conjunto verbalizado grande e criativo é um sistema de relações muito complexo e multiplanar. Na relação criadora com a língua não existem palavras sem voz, palavras de ninguém. Em cada palavra há vozes às vezes infinitamente distantes, anônimas, quase impessoais [...], quase imperceptíveis, e vozes próximas, que soam concomitantemente.

Vê-se, portanto, que não há enunciado que não seja repleto de vozes de outros/as na construção do significado em interação. Essa intertextualidade é um elemento constitutivo de qualquer texto que, para ser inteligível, deve ecoar as vozes presentes na cultura circundante. Obviamente, a comunicação não é simplesmente uma repetição de vozes encontradas prontas pelos/as falantes. Muito pelo contrário. Bakhtin (2003) observa que a intertextualidade é também um espaço para exercício da criatividade dos/as interagentes. Ao ecoar palavras alheias em seus enunciados, os/as falantes não apenas copiam o que já foi dito, mas as recriam e, assim, moldam seu discurso aos/as seus/suas

11. Embora esteja ciente das imbricações conceituais e teóricas que diferenciam esses termos, utilizo, neste texto, os dois termos de modo intercambiável. 
interlocutores/as e ao contexto em que estão interagindo. "Essas 'palavras alheias' são reelaboradas dialogicamente em 'minhas palavras' com o auxílio de outras 'palavras alheias' [...] e em seguida [nas] minhas palavras [...], já de índole criadora" (Bakhtin, 2003:402). Desse modo, os/as interagentes têm a possibilidade de remodelar as vozes alheias presentes em seus enunciados, tornando-as suas, a partir de um processo criativo de adaptação dessas vozes à interação corrente.

O conceito de intertextualidade é aqui utilizado para tentarmos entender a produção discursiva de identidades de gênero e de sexualidade das interventoras em sua relação dialógica com as travestis com quem trabalham. Sandra e Márcia, indivíduos que cotidianamente constroem-se como mulheres em gênero e sexo, heterossexuais, brancas, de classe média, parecem ser levadas, em suas interações com as travestis, a suspender essas identidades e construir identidades ligadas ao universo da prostituição travesti. Veremos que essa construção só é possível pelo caráter intertextual das identidades sociais que, através de ecos de outros discursos identitários presentes nos enunciados das falantes, disponibiliza uma variedade de posições de sujeito para as interventoras apropriarem-se temporariamente.

\section{INTERTEXT(SEX)UALIDADE: VOZES DE GÊNERO E SEXUALIDADE NA PRE- VENÇÃO DE DST/AIDS ENTRE TRAVESTIS}

É tempo de vermos, mais concretamente, como as interventoras da ONG-Liberdade constroem intertextualmente identidades de gênero e sexualidade pertencentes ao universo travesti. Nessa seção, ponho sob escrutínio os enunciados produzidos por Sandra e Márica, mulheres, heterossexuais, brancas, de classe média que as posicionam em discursos que constituem o universo da prostituição travesti na Cidade do Sul. As identidades construídas pelas interventoras são produzidas por intertextos que ligam seus enunciados ao universo lingüístico-identitário que constitui e universo social das travestis colaboradoras desta pesquisa.

As intervenções são tipicamente estruturadas a partir da identidade institucional das interventoras que, ao encontrarem as travestis, orientam as interações à entrega dos preservativos e a recados sobre as reuniões da ONG-Liberdade que acontecem no dia seguinte. A estrutura seqüencial das intervenções organiza-se com base em pares adjacentes (Sacks, Schegloff \& Jefferson, 1974) dos tipos cumprimento-cumprimento, convite para a reunião-aceite/recusa, informação sobre a reunião-indicação sobre a com- 
preensão dessa informação, despedida-despedida. Como pude observar durante minha incursão etnográfica no universo trans (Benedetti, 2005), os turnos dessas interações são engatados o que as torna rápidas e dinâmicas. A entrega dos preservativos não é comumente verbalizada. Márcia, quando uma travesti aproxima-se da janela do carro, somente estende a mão e entrega as camisinhas (ação indicada por * na transcrição). No entanto, interventoras e travestis também constroem interações nas quais conversam sobre suas vidas pessoais e sobre questões pertinentes ao trabalho das travestis nas suas áreas de prostituição. Assim, a identidade institucional das interventoras é temporariamente apagada, o que possibilita a construção de intertextos que, como tento descrever neste artigo, alocam as ativistas da ONG em categorias identitárias associadas ao universo travesti.

No excerto 1 abaixo, Sandra constrói duas identidades diferentes: a de travesti e a de cliente de travesti. A interventora ecoa, em seus enunciados, vozes de identidades díspares em poucos turnos da interação. ${ }^{12}$

\begin{tabular}{|c|c|}
\hline \multicolumn{2}{|l|}{ Excerto 1} \\
\hline Daniela: & $\begin{array}{l}\text { ai guria, peguei um gripão que Deus } \\
\text { e esse vento maldito ainda pra [ajud }\end{array}$ \\
\hline \multicolumn{2}{|l|}{ Sandra } \\
\hline Daniela: & = não vai nada. \\
\hline Sandra: & oi princesa. \\
\hline Karla: & vai tê reunião [amanhã?] \\
\hline Márcia: & tudo bom?]* \\
\hline Sandra: & tem reunião amanhã. \\
\hline Márcia: & $\begin{array}{l}\text { amanhã tem. } \\
(1.2)\end{array}$ \\
\hline Sandra: & $\begin{array}{l}\text { vamo se aqüendá tudo lá. } \\
(0.8)\end{array}$ \\
\hline Daniela: & vamo aqüendá o baco lá também?= \\
\hline Sandra: & =também! \\
\hline Daniela: & @@@@@ \\
\hline
\end{tabular}

12. As convenções de transcrição são as seguintes: MAIÚSCULAS: volume mais alto, ? entonação crescente, * entrega de preservativos, [ ]: sobreposição de falas, - palavra ou enunciado truncado,@@: risos, = falas engatadas, :::.: som prolongado, (0.0) tempo em décimos de segundo durante o qual não há fala, (( )) comentários do analista. 
Márcia:

Karla:

Sandra: ó, uma sacolinha pra colocá o lixo.

ai, arrasô=

=isso se chama profissional educada. Jogue o lixo no lixo

Nesse exemplo, após o enquadre de intervenção ter sido estabelecido, na linha 18, Daniela introduz outro enquadre (Goffman, 1974), o de conversa cotidiana, o que possibilita a negociação discursiva de identidades que extrapolam a institucionalidade das interventoras nesse contexto. Esse novo enquadre é contextualizado (Gumperz, 2002) pelo termo de referência "guria" (L.18), que, na região sul do Brasil, é associado à intimidade e à igualdade do status interacional. Dessa forma, o termo de endereçamento "guria", configura uma troca situacional de códigos (Blom \& Gumperz, 2002) no sentido de que ao ser proferido instaura (1) um novo enquadre e (2) uma nova relação social entre interventora e travesti.

Na linha 23, Sandra, ao notar a aproximação de Karla, a cumprimenta utilizando um enunciado que, segundo minhas informantes travestis, é típico de seus clientes, "oi princesa". Dessa forma, a interventora faz uso da voz dos clientes das travestis na sua construção identitária durante essa interação apropriando-se de "palavras alheias" e reelaborando-as em "suas palavras" (Bakhtin, 2003) ajustando, assim, sua identidade ao contexto onde a interação ocorre.

Ao aproximar-se Karla re-introduz o enquadre intervenção ao perguntar se "vai ter reunião amanhã" (L. 24) ${ }^{13}$ e ao receber os preservativos de Márcia (L. 25). Contudo, essa intervenção já havia sido re-enquadrada (L.18) o que possibilita a negociação de variados intertextos identitários. Isso é ilustrado na linha 29 quando Sandra efetua uma alternância metafórica de códigos (Blom \& Gumperz, 2002) utilizando uma linguagem cifrada comum entre as travestis, o bajubá ${ }^{14}$, construindo, através da voz das travestis, o que Bucholtz e Hall (2004:495) denominam semelhança suficiente, apagando diferenças identitárias que podem ser vistas como prejudicais à interação em favor de posições de sujeito atreladas ao contexto de sua produção. Ao fazer uso do bajubá, Sandra

13. Durante as intervenções, Sandra e Márcia, além de entregar preservativos, anunciam às travestis que encontram a realização da reunião semanal da Liberdade que acontece no dia posterior às intervenções.

14. O bajubá (ou bate) é composto por termos de algumas línguas africanas, principalmente o ioruba-nagô, sobre a base fonológica e gramatical do português. Ademais, há grande freqüência de termos metonímicos e palavras estrangeiras foneticamente adaptadas ao português (ver, Silva, 1993; Astral, 1996; Kulick, 1998; Benedetti, 2005; Pelúcio, 2005, 2007). 
parece diminuir suas diferenças identitárias para construir-se, à luz desse intertexto, como semelhante às travestis com quem interage. Esse processo de apagamento de características ideologicamente discordantes pode ser considerado como uma estratégia utilizada pela interventora na produção intertextual de uma performance identitária que não destoe do contexto onde está inserida durante as intervenções e de suas interlocutoras. Dessa forma, Sandra posiciona-se, intertextualmente, ao falar "vamo se aqüendá tudo lá", como travesti. ${ }^{15}$

O processo de adequação engendrado na administração das diferenças entre interventoras e travestis, através do qual as performances identitárias habitualizadas das mulheres que entregam preservativos às travestis são temporariamente suspensas, é local e seqüencialmente construído. O vocativo "princesa" (L. 23), utilizado por Sandra, posiciona a interventora em intertextos que, segundo as travestis colaboradoras desta pesquisa, são associados aos homens que procuram seus serviços sexuais. Assim, uma identidade de cliente de travesti emerge de tal enunciado. Sandra, na interação acima, igualmente produz, em poucos turnos da interação, uma performance de travesti ao efetuar uma mudança de códigos (Blom \& Gumperz, 2002) entre o português e a linguagem cifrada das travestis, o bajubá. Tais intertextos são recorrentes durante as intervenções. No excerto abaixo, vemos Sandra e Márcia fazendo uso de vocativos e de enunciados típicos entre travestis em uma interação com Adriana, uma travesti que, à época desta interação, havia recentemente colocados silicone nos seios.

Excerto 2

((pára o carro))

Adriana: e aí Sandra?

Sandra: querida::[:

Márcia: [oi mona LUxo! Tu[do bom?

Adriana:

Sandra: ah não que é isso? [tudo bom meu anjo?/

Sandra: ((seis linhas omitidas))

Adriana: e esses óculos de intelectual?

Sandra: ah agora eu to intelectual. @ @ @

Márcia: olha só os apeti da:: da mona! arraSÔ ai meu deus.

Adriana: ((treze linhas omitidas)) sim. daí amanhã eu faço auto-escola e eu solto às quatro.

15. "Vamos se aqüendá tudo lá" pode ser traduzido por "vamos nos encontrar lá". 
Sandra:

Márcia:

Adriana:

Sandra: sim.

Márcia:

Adriana:

Márcia:

Adriana:

Sandra: ta querida! ((aponta para os seios de Adriana)) ta né meu bem!

ahta@@@@ daqui um pouco sou EU que também vai fazê um as@@[@@@@@ [ah ta. obrigada Sandra. tchau. até amanhã. até amanhã. ((dá partida no carro))

$\mathrm{Na}$ interação acima, os trânsitos por discursos de identidades acontecem com base em posicionamentos discursivos que constroem as interventoras como travestis através do uso de enunciados comuns entre as travestis participantes deste estudo. Márcia, na linha 4, cumprimenta sua interlocutora com "oi mona luxo". Tal forma de endereçamento é típica entre as travestis da Cidade do Sul que, ao se encontrarem, freqüentemente se referem umas às outras por "mona luxo", forma que enfatiza o glamour de sua construção corporal e suas vestimentas. Alguns turnos adiante é a vez de Sandra engajar-se na encenação de uma identidade travesti. Nessa noite, Adriana usava somente sapatos de saltos altos e uma bermuda jeans. A parte superior de seu corpo estava descoberta e a travesti exibia seus enormes seios à procura de clientes. Na linha 14, a advogada da ONG Liberdade orienta-se para os seios recém adquiridos por Marcinha, surpresa com a quantidade de silicone utilizado. Ao afirmar "olha só os apeti da mona", Sandra faz uso da palavra apeti que significa seio em bajubá e, dessa forma, constrói-se como uma travesti conhecedora dessa linguagem cifrada através de um intertexto que a associa ao universo trans (Benedetti, 2005).

$\mathrm{O}$ excerto 2 nos apresenta a suspensão temporária das identidades tradicionais das interventoras que, ao posicionarem-se em discursos ligados ao universo travesti, encenam performances de identidades que povoam tal lócus sócio-cultural. Tal suspensão materializa-se através da utilização de termos indiciais (Ochs, 1992) que ao serem proferidos produzem as interventoras como participantes de grupos identitários específicos, i.e, como travestis, como cliente de travesti e como profissional do sexo.

O uso do bajubá é talvez a ferramenta lingüística mais freqüentemente utilizada pelas interventoras na negociação de suas posições-de-sujeito na batalha. Ao fazerem uso desse código, as interventoras convergem no uso de linguagem (Bortoni-Ricardo, 1984) com as travestis, construindo-se, assim, no mesmo universo social que suas interlocutoras transgênero. Vejamos mais 
esse exemplo, no qual Sandra faz uso fluente da linguagem cifrada das travestis em sua construção identitária.

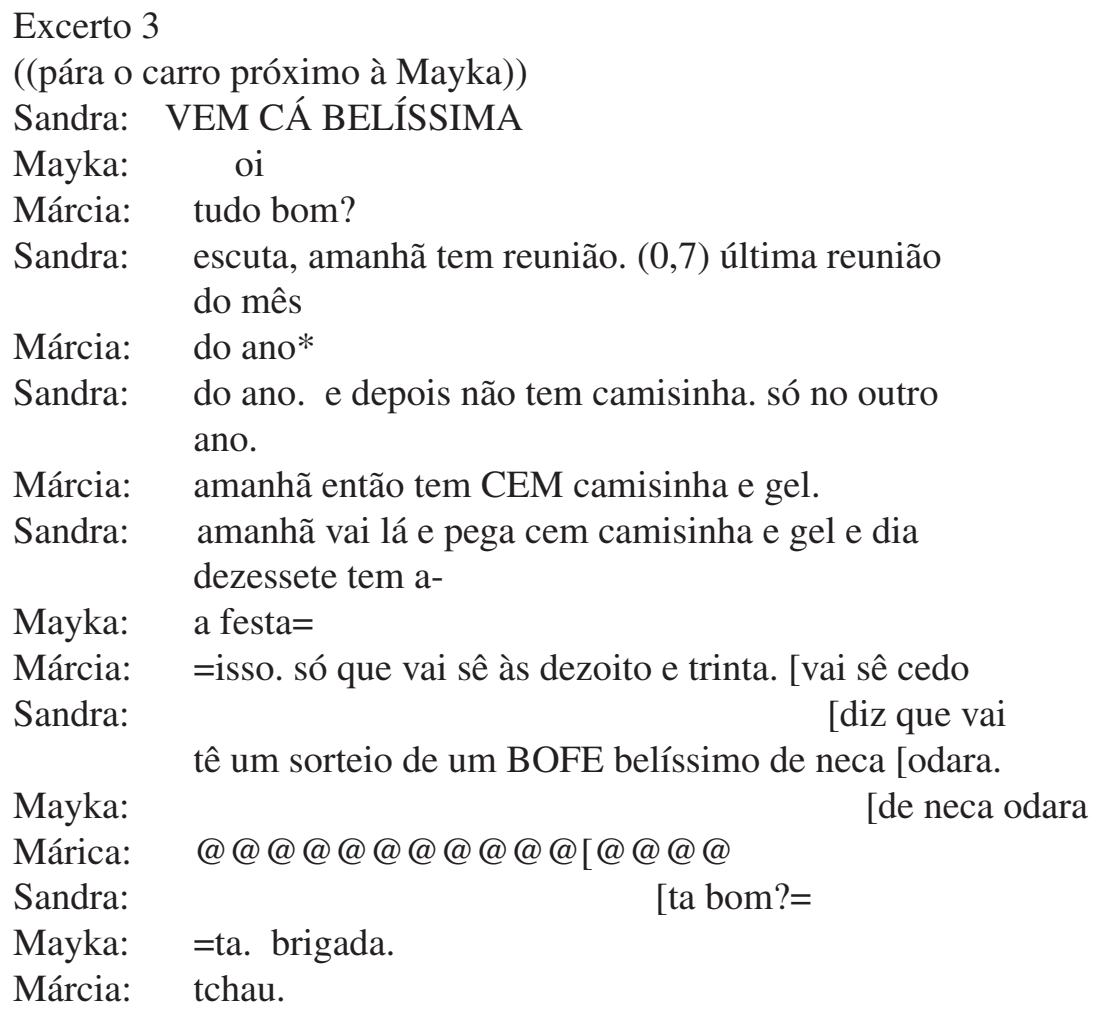

Essa intervenção foi gravada em novembro de 2003 quando a equipe da ONG Liberdade se preparava para encerrar os projetos financiados pelos governos Federal e Estadual, limitando-se, a partir de então, a questões burocráticas e administrativas a serem resolvidas na sede da instituição. Aproveitando sua incursão na noite, Sandra e Márcia durante essa noite avisavam as travestis sobre a última reunião do ano e sobre a festa de lançamento de um livro que a ONG estava organizando. No dia posterior a essa intervenção, haveria a distribuição de um grande número de preservativos e as interventoras tentavam convencer suas interlocutoras a participar desse encontro para abastecer seu estoque de camisinhas e saches gel lubrificante. Dessa forma, a identidade institucional de Sandra e Márcia é uma constante construção no excerto acima (L. 4-14) e emerge de sua orientação ao anúncio de questões relativas ao funcionamento da ONG. No entanto, nas linhas 15 e 16, Sandra, provavelmente 
com o intuito de convencer Mayka a participar da "última reunião do ano", alterna códigos, posiciona-se em discursos do bajubá e, assim, engendra a encenação de uma identidade travesti, deixando temporariamente de lado sua identidade institucional anteriormente construída. Afirmando que, segundo boatos, haveria o sorteio de "um bofe belíssimo de neca odara", Sandra parece tentar motivar sua interlocutora travesti a participar da reunião. Esse enunciado indica que um belo homem com grande órgão sexual estaria à disposição das travestis presentes na reunião. Mayka orienta-se a esse fato e co-constrói o turno de Sandra através de uma sobreposição de falas (L.17).

A construção de identidade de gênero e sexualidade efetuada por Sandra através desses intertextos, nos mostra que as identidades, de modo geral, são intertextuais par excellence, o que corrobora as idéias de Bakhtin sobre o caráter intertextual dos textos. Nas palavras do filósofo russo, "nosso discurso, isto é, todos os enunciados [...], é pleno de palavras dos outros [...]. Essas palavras dos outros trazem consigo sua expressão, o seu tom valorativo que assimilamos, reelaboramos e reacentuamos" (Bakhtin, 2003:295). Assim, as interventoras, ao fazer uso de enunciados ligados aos clientes das travestis e às travestis, apropriam-se de formas lingüísticas que as constroem como participantes dessas categorias identitárias. Vemos, então, que as performances (Butler, 2003) de identidades de gênero e sexualidade encenadas por Sandra e Márcia são elaboradas através de intertextos que alocam as interventoras em lugares sociais aos quais elas não pertencem quando estão fora de seu trabalho na ONG-Liberdade.

Em linhas gerais, os excertos acima ilustram a fluidez das posições de sujeito adotadas por Sandra, e em menor grau Márcia, a partir de intertextos ligados ao universo das travestis. As interventoras engajam-se em um processo local de suspensão de sua identidade institucional e constroem-se (1) como cliente de travesti e (2) como travesti. Como vimos, a partir da análise dos intertextos utilizados pelas interventoras, ao fazer uso de enunciados convencionalmente ligados às travestis e seus clientes, Sandra e Márcia parecem re-ajustar suas identidades tradicionais de interventoras e mulheres de classe média ao contexto onde a interação está inserida.

Outro exemplo da construção intertextual de identidades pode ser visto no excerto que segue, no qual interventora e travesti engendram, conjuntamente, uma performance identitária de profissional do sexo para Sandra. Essa performance emerge através de intertextos lingüísticos e extralingüísticos que constroem a interventora como prostituta. 
Excerto 4

Sandra:

Qualqué dia desse vô ficá na tua esquina. [tem lugar]pra mim?=

Daniela: [pode ficá] =com certeza. Claro. Tu sabe que sempre tem pra ti $=$

Sandra: =ta. Me diz uma coisa. Que cor o meu espartilho?

Márcia:@@@[@

Daniela: $\quad$ que que é?=

Sandra: $\quad=$ MEU ESPARtilho né!

Daniela: Lógico. Bem vermelho, bem puta, bem tudo=

Sandra: =ta. E tu vai me ensiná aquele jogo assim?=

Daniela: $\quad=$ ensino.

Márcia:@@@@@@@@@

Sandra: ah bom.

Daniela: um jogo pra balançá TUDO que tem direito= Sandra: $\quad$ bom. Se eu começá a balançá [muito PLAFT cai tudo.

Daniela: [ A:::I:[:: não pode balançá.

Márcia: [@@@@@

No contexto que imediatamente precede essa interação, Sandra e Daniela discutiam sobre a quantidade de clientes que circulavam a área. Daniela afirma que o número é bom e que tem feito uma quantia razoável de dinheiro. Deparada com tal informação, Sandra afirma que vai dividir com Daniela seu ponto (L. 38). A travesti afirma que Sandra tem passagem livre nesse contexto e que, se quiser, pode prostitui-se ali. É nesse enquadre que a interventora, sublinhando o poder simbólico da travesti nesse contexto, pede a Daniela conselhos sobre sua vestimenta: "que cor o meu espartilho?" (L. 42). Daniela parece não ter entendido o que Sandra afirmou (afinal, como uma advogada poderia pedir tal informação?) e, na linha 45 , pede à interventora que repita a pergunta. Sandra imediatamente reitera, em volume mais alto, a informação que precisa (L. 46). É aí que Daniela consolida o intertexto recém produzido por Sandra dizendo que para ser prostituta (e ter muitos clientes) ela deve usar um espartilho "bem vermelho, bem puta, bem tudo".

No Excerto 4, Sandra e Daniela co-constroem a performance de prostituta sugerida pelo enunciado utilizado pela interventora na linha 38. Essa construção é elaborada pelas interlocutoras a partir de atos de fala (Austin, 1976) (i.e. conselhos sobre vestimenta, pedido de permissão para compartilhar 
o território de prostituição) e signos que apontam (Ochs, 1992; Bucholtz \& Hall, 2003) para uma identidade específica: a identidade de prostituta. Com isso, Sandra e Daniela atualizam a identidade da interventora através do uso de formas lingüísticas e referências a insígnias da identidade de prostituta desconstruindo, assim, as posições sociais de classe, profissão e gênero tradicionais adotadas por Sandra no seu dia-a-dia. As intervenções constituem, nessa perspectiva, jogos de linguagem (Wittgenstein, 2005 [1953]) cujas regras são organizadas dialogicamente entre interventoras e travestis a partir da negociação de múltiplas identidades. No caso em tela, Sandra, deparada com o sucesso financeiro de sua interlocutora travesti, apropria-se de vozes que a constroem como profissional do sexo para apagar diferenças percebidas como díspares e construir-se como uma participante do mosaico identitário que constitui o mercado de prostituição da cidade do Sul.

A construção intertextual de uma performance de prostituta elaborada conjuntamente por interventora e Daniela continua nas linhas 48-53 nas quais Sandra pede a Daniela que a ensine um movimento corporal utilizado pelas travestis para exibir seus atributos físicos (colocando as mãos nos quadris, balançando os seios e mexendo lentamente a cabeça para jogar os cabelos de um lado para o outro). A referência a essa prática corporal nos mostra Sandra valendo-se de um intertexto extra-lingüístico na construção de sua performance e, sublinhando, assim, o capital simbólico de Daniela nesse contexto. Tal intertexto parece funcionar como uma tática de validação (Bucholtz e Hall, 2003, 2004) da identidade de Daniela como prostituta eficiente, i.e. que conhece as práticas simbólicas e corporais valiosas em seu ponto de prostituição. Essa validação é enfatizada na linha 54 na qual Sandra menospreza sua própria capacidade para elaborar tal prática corporal ("se eu começá a balançá PLAFT cai tudo") orientando-se desfavoravelmente a sua performance e deixando implícita, em comparação com Daniela, sua inabilidade para tal tarefa. A travesti, defrontada com a ineficiência da performance de Sandra, consolida sua superioridade de gênero indicando que Sandra "não pode balançar" (L. 55) o corpo do jeito que ela o faz. Essa negociação é interrompida no momento que um possível cliente passa de carro pelas interlocutoras. Daniela, sem titubear, o chama e, exibindo seu corpo, engaja-se no movimento que impossibilita Sandra de encenar, intertextualmente, uma performance de eficiente profissional do sexo. 


\section{ConsideraÇÕes FinAIS}

Nas últimas décadas, pesquisadores/as têm tentado descrever as configurações culturais e as posições sociais de indivíduos transgêneros nos mais diversos contextos sócio-históricos. Estudos etnográficos sobre tal fenômeno ${ }^{16}$ têm investigado como as/os transgêneros cruzam as fronteiras de gênero (Louro, 2001) nas práticas sócio-culturais, corporais e simbólicas de que participam. A literatura disponível parece indicar que os/as transgêneros usam a linguagem fluidamente e, dessa forma, marcam afiliações com diferentes posições culturais locais de seus milieux específicos, i.e. identidades globais vs. identidades locais (Besnier, 2003), masculinidade vs. feminilidade (Livia, 1997; Borba \& Ostermann, 2007), poder vs. solidariedade (Hall \& O’Donovan, 1996).

Com a onda de interesse pelo fenômeno da transformação de gênero, iniciada na antropologia, importantes documentações sobre o uso da linguagem entre indivíduos transgêneros foram elaboradas. Esses estudos têm enfatizado que uma das dinâmicas que o fenômeno transgênero promove na vida social é mostrar, através de corpos e discursos, a permeabilidade das fronteiras entre os gêneros (Kulick, 1998, 1999; Benedetti, 2005; Livia, 1997; Hall, 2002, entre outros/as). Contudo, essas pesquisas têm, em sua grande maioria, investigado dados de entrevistas entre transgêneros ou entre transgêneros e pesquisadores/as, deixando de lado a importância de conversas espontâneas entre esses indivíduos e as pessoas que fazem parte de seu contexto cultural. Em uma extensa e minuciosa revisão da literatura dos estudos sobre as relações entre transgênero e a linguagem, o antropólogo Don Kulick (1999) observa a infeliz ausência de pesquisas, com dados naturalísticos de conversas espontâneas, sobre como os/as transgêneros conversam com as pessoas que constituem seu universo social. Kulick (1999:615) sugere que "precisamos saber mais sobre como os indivíduos transgêneros falam com outras pessoas em seus milieux, e precisamos saber como essas pessoas avaliam e respondem a essa fala" (p. 615).

Seguindo a sugestão de Kulick, neste estudo, investigam-se as dinâmicas discursivo-identitárias emergentes de embates interacionais entre duas mulheres ativistas de uma ONG criada por e para travestis e as travestis pro-

16. Veja, por exemplo, os estudos sobre as mabu taitianas (Levy, 1971); sobre as xanith de Omã (Wikan, 1978); sobre as panemas paraguaias (Clastres, 1990); sobre as berdache norteamericanas (Epple, 1998); e outras ocorrências múltiplas de transformações de gênero em várias sociedades (Bolin, 1988; King, 1993; Mckenzie, 1994; Shapiro, 1991). 
fissionais do sexo de uma cidade do sul do Brasil. Guiado por uma perspectiva não-representacional da linguagem proposta por Wittgenstein e pela teoria bakhtiniana da intertextualidade, este artigo descreve como identidades (de gênero e sexualidade) são construídas com base em intertextos que ligam as interventoras a identidades que povoam o universo trans (Benedetti, 2005). Já que os significados (e as identidades a eles relacionados) não são inerentes às palavras (e aos indivíduos), mas construídos no uso delas feitas em um contexto sócio-histórico, Sandra e Márcia têm a oportunidade de fazer uso de certas vozes para adequar sua posição-de-sujeito à zona de batalha travesti. Vimos que as interventoras trazem, em seus enunciados, vozes de travesti, de cliente de travesti e de profissional do sexo, identidades que não são constantes em seu repertório identitário cotidiano. Essas identidades são apenas trazidas ao discurso das ativistas de ONG Liberdade por ocasião das intervenções nas quais há o confronto de identidades tradicionais e não-tradicionais. Como nesse contexto as travestis têm capital simbólico (Bourdieu, 1985) por fazer parte das práticas ali construídas, as interventoras parecem ser forçadas a transitar por uma multiplicidade de identidades e, assim, não destoar completamente do contexto onde se encontram durante as intervenções.

O confronto de identidades tradicionais e não-tradicionais construido nas zonas de prostituição de travesti da Cidade do Sul parece um rico milieu para a construção intertextual de identidades de gênero e sexualidade. Mais significativamente, a apropriação de vozes que ecoam categorias identitárias ligadas ao universo das travestis da Cidade do Sul elaborada por Sandra e Márcia parece configurar uma estratégia para produzir discursivamente uma semelhança suficiente (Bucholtz e Hall, 2003, 2004) entre interventoras e as travestis. Através das análises apresentadas podemos inferir que os intertextos utilizados pelas interventoras são adotados para indicar que, nesse contexto, a identidade mais empoderada, aquela que molda as regras identitárias dos jogos de linguagem das intervenções, é a identidade travesti. Esse fenômeno é bem exemplificado nos excertos acima nos quais vemos Sandra e Márcia suspender temporariamente suas identidades tradicionais de mulheres de classe média, heterossexuais, mães, através dos intertextos, por identidades não-tradicionais (travesti, cliente, prostituta) sublinhando, dessa forma, as posições de suas interlocutoras durante as intervenções. 


\section{REFERÊNCIAS BIBLIOGRÁFICAS}

Astral (Associação de Travestis e Liberados). Diálogo de bonecas. Rio de Janeiro: Astral, 1996.

Austin, J. L. How to do things with words. Oxford: Oxford University Press, 1976.

Bakhtin, M. (Voloshinov). Marxismo e filosofia da linguagem. Tradução de Michel Lahud et alii. São Paulo: Hucitec, 1997 [1929].

Bakhtin, M. Estética da criação verbal. Tradução Paulo Bezerra. São Paulo: Martins Fontes, 2003.

Bakhtin, M. O Freudismo.São Paulo: Perspectiva, 2004.

Benedetti, M. R. Toda Feita: o corpo e o gênero das travestis. Rio de Janeiro: Garamond, 2005.

Besnier, N. Crossing genders, mixing languages: The linguistic construction of transgenderism in Tonga. In: Holmes, J. \& Meyerhoff, M. (Eds.), Handbook of language and gender. Oxford: Blackwell, 2003. pp. 279-301.

Blom, J.-P.; Gumperz, J. O significado social na estrutura lingüística: alternância de códigos na Noruega. In: Ribeiro, B. T. \& Garcez, P. M., Sociolingüística interacional, $2^{a}$ ed. São Paulo: Loyola, 2002, pp. 45-84.

Bolin, A. In search of Eve: Transsexuals' rites of pasage. South Hadley, MA: Bergin and Garvey, 1988.

Borba, R.; Ostermann, A. C. Do bodies matter? Travestis' embodiment of (trans)gender identity through the manipulation of the Brazilian Portuguese grammatical gender system. Gender and Language, 1(1): 131-147, 2007.

Bortoni-Ricardo, S.M. Problemas de comunicação interdialetal. Tempo Brasileiro, 78/79, 9-32, 1984.

Bourdieu, P. The social space and the genesis of groups. Theory and Society, 14: 723744, 1985.

Brait, B. Bakhtin e a natureza constitutivamente dialógica da linguagem. In: Brait, B. (Org.). Bakhtin, dialogismo e construção de sentido. Campinas: Unicamp, 1997, pp. 91-104.

Bucholtz, M. Why be normal? Language and identity practices in a community of nerd girls. Language in Society, 28(2):203-223, 1999.

Bucholtz, M.; Hall, K. Language and Identity. In: Duranti, A.(ed.). A companion to Linguistic Anthropology. Oxford: Basil Blackwell, 2003, pp. 268-294.

Bucholtz, M.; Hall, K. Theorizing identity in language and sexuality research. Lan- 
guage in Society, 33 (4):449-515, 2004.

Butler, J. Problemas de gênero: feminismo e subversão da identidade. Rio de Janeiro, Civilização Brasileira, 2003.

Cameron, D. Working with spoken discourse. London: Sage, 2001.

Clark, K. \& Holquist, M. Mikhail Bakhtin. São Paulo:Perspectiva, 1998.

Clastres, P. A sociedade contra o Estado. Rio de Janeiro: Francisco Alves, 1990.

Condé, M. L. Wittgenstein: linguagem e mundo. São Paulo: Annabume, 1998.

Davies, B. \& Harré, R. Positioning: The discursive production of selves. Journal for the Theory of Social Behaviour, 20(1): 43-63,1990.

Eckert, P. \& Mcconnell-Ginet, S. Think practically and look locally: Language and gender as community-based practice. Annual Review of Anthropology, 21:461-490, 1992.

Epple, C. Coming to terms with Navajo nadleehi: A critique of berdache, 'gay', 'alternative gender', and 'two spirit'. American Ethnologist, 25(2):267-290, 1998.

Fabrício, B. F. Implementação de mudanças no contexto educacional: discursos identidades e narrativas em ação. Rio de Janeiro: PUC, Departamento de Letras, Estudos de Linguagem. Mimeo. Tese de Doutorado em Estudos da Linguagem, 2002.

Fabrício, B.F. Lingüística Aplicada como espaço de "desaprendizagem": redescrições em curso. In: Moita Lopes, L.P. (Org.). (2006), Por uma Lingüística Aplicada INdisciplinar. São Paulo: Parábola Editorial, 2006, pp. 45-65.

Fabrício, B. F. \& Moita Lopes, L.P. Discursos e vertigens: identidades em xeque em narrativas contemporâneas. Veredas, 4(2):19-42, 2004.

Fairclough, N. Discurso e mudança social. Brasília: Editora da Universidade de Brasília, 2001.

Freitas, M.T. de Assunção. Ciências Humanas e pesquisa: leituras de Mikhail Bakhtin. São Paulo: Cortez, 2002.

Gee, J.P. Social Linguistics and literacies: Ideology in discourses. Bristol:The Falmer Press, 1990.

Gee, J.P. \& Lankshear, C. Language, literacy and the new work order. In: Lankshear, C. (ed.), Changing literacies. Buckingham: Open University Press, 1997, pp. 83102.

Glock, H.J. Dicionário Wittgenstein. Tradução Helena Martins. Rio de Janeiro: Jorge Zahar, 1998.

Goffman, E. Frame analysis. New York: Harper \& Row, 1974. 
Gumperz, J.J. Convenções de contextualização. In Ribeiro, Branca T. \& Garcez, P.M., Sociolingüística interacional, $2^{\mathrm{a}}$ ed. São Paulo: Loyola, 2002, pp.149-182.

Hall, K. "Unnatural" gender in Hindi. In: Hellinger, M. \& Bussman, H. (Orgs.). Gender across languages: The linguistic representation of women and men. Amsterdam: John Benjamins, 2002, p. 133-162.

Hall, K. Intertextual Sexuality: Parodies of class, identity, and desire in Liminal Delhi. Journal of Linguistic Anthropology, 15(1): 125-144, 2005.

Hall, K. \& O'Donovan, V. Shifting gender positions among Hindi-speaking Hijras. In: Bergvall, V.; Bing, J. \& Freed, A. (Eds.), Rethinking language and gender research: Theory and Practice. London: Longman, 1996 pp. 228-266.

King, D. The transvestite and the transsexual: Public categories and private identities. Aldershot: Avebury, 1993.

Kulick, D. The gender of Brazilian transgendered prostitutes. American Anthropologist, 99:547-585, 1997.

Kulick, D. Travesti: sex, gender, and culture among Brazilian transgendered prostitutes. Chicago and London: University of Chicago Press, 1998.

Kulick, D. Transgender and language: A review of literature and suggestions for the future. Journal of Lesbian and Gay Studies, 5:601-622, 1999.

Levy, R. The community function of Tahitian male transvestism: A hypothesis. Anthropological Quarterly, 44(1):12-21, 1971.

Lindstrom, L. Context contests: Debatable truth statements on Tanna (Vanuatu). In: Duranti, A. \& Goodwin, C. (Eds.) Rethinking context: Language as an interactive phenomenon. Cambridge: Cambridge University Press, 1992. pp. 101-124.

Livia, A. Disloyal to masculinity: Linguistic gender and liminal identity in French. In: Livia, A. \& Hall, K. (Orgs.), Queerly phrased: language, gender, and sexuality. New York: Oxford University Press, 1997. pp. 349-368.

Louro, G. L. Teoria Queer: Uma política pós-identitária para a Educação. Revista Estudos Feministas, 9(2):541-553, 2001.

Marcondes, D. Filosofia, linguagem e comunicação.São Paulo: Cortez, 2000.

Martins, H. Sobre a estabilidade do significado em Wittgenstein. Veredas, 4 (2): 1942, 2000.

Mckenzie, G. Transgender Nation. Bowling Green, Ohio: Bowling Green State University Popular Press, 1994.

Moita Lopes, L.P. Discurso, corpo e identidade: Masculinidade hegemônica como comunidade imaginada na escola. Gragoatá, (11):207-226, 2001. 
Moita Lopes, L.P. Identidades fragmentadas. Campinas: Marcado de Letras, 2002.

Moita Lopes, L.P. (Org.) Discursos de identidades. Campinas: Mercado de Letras, 2003.

Moita Lopes, L.P. A construção do gênero e do letramento na escola: como um tipo de conhecimento gera o outro. Investigações: Lingüística e Teoria Literária,17 (2):4768, 2005.

Moita Lopes, L.P. On being white, male and heterosexual in a Brazialian school: Multiple positionings in oral narratives. In. Schiffrin, D.; De Finna, A.; Bamberg, M.(Eds.), Discourse and Identity. Cambridge: Cambridge University Press, 2006, 288-313.

Moreno, A.R. Wittgenstein: os labirintos da linguagem: ensaio introdutório. Campinas. Editora da Unicamp, 2000.

Ochs, E. Indexing gender. In: Duranti, A. \& Goodwin, C. (Eds.), Rethinking context: Language as an interactive phenomenon. Cambridge: Cambridge University Press, 1992, pp. 335-358.

Pelúcio, L. Na noite nem todos os gatos são pardos: Notas sobre a prostituição travesti. Cadernos Pagu, 25:217-248, 2005.

Pelúcio, L. No salto: trilhas e percalços de uma etnografia entre travestis que se prostituem. In: Bonetti, A.; Fleischer, S. (orgs.). Entre saias justas e jogos de cintura. Florianópolis e Santa Cruz do Sul: Editora Mulheres e EDUNISC, 2007, pp. 93-124.

Sacks, H.; Schegloff, E.; Jefferson, G. A simplest systematics for the organization of turn-taking in conversation. Language, 50: 636-735, 1974.

Silva, H.R.S. Travesti: a invenção do feminino.1ed. Rio de Janeiro: Iser, 1993.

Stam, R. Bakhtin: da teoria literária à cultura de massa. São Paulo: Ática, 2000.

Strathern, P. (1997). Wittgenstein em 90 minutos. Trad. M. H. Geordane. Consultoria Danilo Marcondes. Rio de Janeiro: Editora Zahar, 1997.

Wikan, U. The Omani xanith: A third gender role? Man, 13(3):473-475, 1978.

Wittgenstein, L. Investigações filosóficas. São Paulo: Vozes, 2005 [1953].

Aluno do Programa de Pós-Graduação Interdisciplinar de Lingüística Aplicada da Universidade Federal do Rio de Janeiro. Participou nos últimos anos de inúmeros congressos de âmbito nacional e internacional, nos quais apresentou comunicações sobre as relações entre linguagem e identidade entre travestis que se prostituem na região suldo Brasil. borba.rodrigo@terra.com.br 